\title{
A prognostic nomogram for long-term major adverse cardiovascular events in patients with acute coronary syndrome after percutaneous coronary intervention
}

Shuting Kong ${ }^{1}$, Changxi Chen ${ }^{1}$, Gaoshu Zheng ${ }^{1}$, Hui Yao ${ }^{1}$, Junfeng Li', Hong Ye², Xiaobo Wang ${ }^{3}$, Xiang Qu', Xiaodong Zhou', Yucheng $\mathrm{Lu}^{4}$ and Hao Zhou ${ }^{1 *}$ (D)

\begin{abstract}
Background: Accurate prediction of major adverse cardiovascular events (MACEs) is very important for the management of acute coronary syndrome (ACS) patients. We aimed to construct an effective prognostic nomogram for individualized risk estimates of MACEs for patients with ACS after percutaneous coronary intervention (PCI).

Methods: This was a prospective study of patients with ACS after PCI from January 2013 to July 2019 ( $n=2465)$. After removing patients with incomplete clinical information, a total of 1986 patients were randomly divided into evaluation ( $n=1324)$ and validation $(n=662)$ groups. Predictors included in the nomogram were determined by a multivariate Cox proportional hazards regression model based on the training set. Receiver operating characteristic (ROC) curves and calibration curves were used to assess the discrimination and predictive accuracy of the nomogram, which were then compared with those of the classic models. The clinical utility of the nomogram was assessed by X-tile analysis and Kaplan-Meier curve analysis.

Results: Independent prognostic factors, including lactate level, age, left anterior descending branch stenosis, right coronary artery stenosis, brain natriuretic peptide level, and left ventricular ejection fraction, were determined and contained in the nomogram. The nomogram achieved good areas under the ROC curve of 0.712-0.762 in the training set and $0.724-0.818$ in the validation set and well-fitted calibration curves. In addition, participants could be divided into two risk groups (low and high) according to this model.
\end{abstract}

Conclusions: A simple-to-use nomogram incorporating lactate level effectively predicted 6-month, 1-year, and 4-year MACE incidence among patients with ACS after PCI.

Keyword: ACS Nomogram predict MACE Risk

\footnotetext{
*Correspondence: wyzh66@126.com

${ }^{1}$ Department of Cardiology, The First Affiliated Hospital of Wenzhou

Medical University, Wenzhou 325000, Zhejiang, China

Full list of author information is available at the end of the article
}

\begin{abstract}
Background
According to the statistical results of the World Health Organization, coronary artery diseases such as acute coronary syndrome (ACS) have become some of the most frequent causes of death worldwide [1]. ACS includes acute ST-segment elevation myocardial infarction (STEMI), non-ST-segment elevation myocardial infarction (NSTEMI), and unstable angina pectoris (UA) [2].
\end{abstract}

(c) The Author(s) 2021. Open Access This article is licensed under a Creative Commons Attribution 4.0 International License, which permits use, sharing, adaptation, distribution and reproduction in any medium or format, as long as you give appropriate credit to the original author(s) and the source, provide a link to the Creative Commons licence, and indicate if changes were made. The images or other third party material in this article are included in the article's Creative Commons licence, unless indicated otherwise in a credit line to the material. If material is not included in the article's Creative Commons licence and your intended use is not permitted by statutory regulation or exceeds the permitted use, you will need to obtain permission directly from the copyright holder. To view a copy of this licence, visit http://creativecommons.org/licenses/by/4.0/. The Creative Commons Public Domain Dedication waiver (http://creativeco mmons.org/publicdomain/zero/1.0/) applies to the data made available in this article, unless otherwise stated in a credit line to the data. 
Percutaneous coronary intervention $(\mathrm{PCI})$ remains the most effective treatment for ACS [3, 4]. However, the incidence of MACE in patients with different risk factors varies, especially in high-risk cases $[5,6]$. A predictive model would allow physicians to better identify patients at elevated risk, which would facilitate a more personalized approach to managing these cases.

Several cardiovascular disease risk and prognosis assessment tools have been established in different populations to guide clinical practice [7-14]. GRACE and Thrombolysis in Myocardial Infarction (TIMI) risk scores are recommended in the guidelines for predicting cardiovascular outcomes (short- and medium-term) for patients with ACS [7, 15-17]. The CADILLAC risk score is used to predict 30-day and 1-year mortality after PCI for acute myocardial infarction (AMI) [8]. Unfortunately, clinical risk stratification for long-term MACEs for patients with ACS after PCI is not well defined.

In recent years, an increasing number of studies have focused on laboratory testing indicators to predict the prognosis of diseases. Several recent studies have shown that lactate level is an independent prognostic factor that is useful for identifying patients at high risk [18-21]. Our purpose in designing a nomogram incorporating lactate was to provide a tool for the clinical evaluation of patients with ACS undergoing PCI.

\section{Methods}

\section{Patient selection}

The prospective study was approved by the Ethics Committee of the First Affiliated Hospital of Wenzhou Medical University. All study subjects provided informed consent. From January 2013 to July 2019, a total of 2465 patients in the Cardiovascular Department of the First Affiliated Hospital of Wenzhou Medical University were diagnosed with ACS and underwent PCI.

ACS is diagnosed according to current American Heart Association (AHA)/American College of Cardiology (ACC) guidelines, including STEMI and non-ST-segment elevation acute coronary syndrome (NSTE-ACS) [22, 23]. STEMI was defined as continuous chest pain that lasted $>30 \mathrm{~min}$, arrival at the hospital within $12 \mathrm{~h}$ from the onset of symptoms, ST-segment elevation $>0.1 \mathrm{mV}$ in $\geq 2$ contiguous leads or new left bundle-branch block on the 12-lead electrocardiogram, and elevated cardiac markers (creatine kinase-MB or troponin I) [22]. NSTEACS included NSTEMI and UA. NSTEMI was defined as ischemic symptoms in the absence of ST-segment elevation on the electrocardiogram with elevated cardiac markers. UA was defined as having newly developed/ accelerating chest symptoms on exertion or rest angina within 2 weeks without biomarker release [23]. The exclusion criteria were as follows: (1) chronic coronary syndrome; (2) tumour history; (3) significant comorbidity, trauma, or surgery; (4) incomplete follow-up data; and (5) death within the first month.

According to these inclusion and exclusion criteria, 1986 patients were included in the study. Patients followed for 4 years were randomly divided into the training $(n=1324)$ and validation sets $(n=662)$ based on a computer-generated randomly generated allocation sequence. All methods were carried out in accordance with approved guidelines.

\section{Clinical outcomes definitions}

MACE was defined as the end point of this study and refers to all-cause mortality, clinically driven re-vascularization of target lesions, and new or recurrent myocardial infarction and stroke.

\section{Collection of demographic, clinical, and follow-up data}

All data were extracted from the electronic medical record system. Demographic data included sex and age. The preoperative clinical indicators included left anterior descending branch (LAD) stenosis $\geq 50 \%$, left circumflex artery (LCX) stenosis $\geq 50 \%$, right coronary artery (RCA) stenosis $\geq 50 \%$ (according to TIMI criteria [16]), three-vessel disease (LAD, LCX and RCA all with stenosis $\geq 50 \%$ ), serum lactate level, serum brain natriuretic peptide (BNP) level, estimated glomerular filtration rate (EGFR), serum creatinine level, haemoglobin (HB), serum uric acid level, and left ventricular ejection fraction (LVEF). Blood samples were drawn from peripheral venous blood immediately upon admission and tested at the hospital's central laboratory. The maximum values of lactate and BNP were taken before coronary angiography. EGFR was calculated using the Chronic Kidney Disease Epidemiology Collaboration (CKD-EPI) equation [24]. LVEF was obtained by echocardiography measured in 2D-biplane at hospital admission (before PCI) $[25,26]$. Medical history included hypertension, diabetes, peripheral artery stenosis, atrial fibrillation, previous stroke, and kidney disease. Stenosis of the LAD, LCX and RCA was determined by coronary angiography during hospitalization. Killip class I was defined as the absence of congestive heart failure, class II as the presence of rales and/ or jugular venous distention, class III as the presence of pulmonary oedema, and class IV as cardiogenic shock.

Regular medical follow-up data were obtained by telephone and clinic visits. Patients in the training set and the validation set were followed up for four years.

\section{Statistical analysis}

Continuous variables with a normal distribution are expressed as the mean \pm standard deviation $(\bar{x} \pm s)$, and Student's t-tests were used to compare the differences 
between the training and validation sets. The nonnormally distributed data are described as the median and 25 th and 75th percentiles, and comparisons of the two sets were carried out with the Mann-Whitney U-test. Categorical variables are expressed as frequencies (proportions), and descriptive comparisons were made using Pearson's $X^{2}$ test or Fisher's exact test if one of the expected values in the $2 \times 2$ table was $<5$. Differences in the event rates at different time points after PCI were assessed using the $x^{2}$ test. The associations of these variables with MACEs were identified using Cox proportional hazards regression models. Forward stepwise selection (likelihood ratio) with the Akaike information criterion (AIC) was used to select variables for the multivariable Cox proportional hazards regression models. The results are reported as hazard ratios (HRs) and 95\% confidence intervals (CIs). The identified variables based on the results of multivariate analysis were incorporated to construct the nomogram to predict the risk of MACEs at 6 months, 1 year and 4 years after PCI using statistical software (rms in R, version 3.6.2; http://www.r-proje ct.org). With the input of independent risk factors, the nomogram outputs a risk score for each patient.

The area under the receiver operating characteristic curve (AUC) of the time-dependent receiver operating characteristic curve (tdROC) varies as a function of time [27]. TdROC was estimated for comparing the discrimination (predictive capability) of the nomogram, CADILLAC risk score and GRACE risk score [28]. The accuracy of calibration was assessed by plotting the nomogrampredicted and observed MACE rates based on the population quartiles of predicted risk. In addition, we analysed the potency of this model to stratify patients at high risk for MACEs.

All data management and statistical analysis were performed using SPSS 20.0, MedCalc 19.0.5 and R 3.6.2. X-tile 3.6.1 was used to obtain cut-off values [29]. All tests were performed 2-tailed at a significance level of $5 \%$.

\section{Role of the funding source}

This research was funded by the National Natural Science Foundation of China (No. 81873468). The sponsor $(\mathrm{ZH})$ played a role in the research design and review.

\section{Results}

\section{Baseline characteristics of patients and outcomes}

A total of 1986 patients with ACS treated with PCI were included in this study after excluding those with missing data. The training set comprised 1324 patients, with 662 patients in the validation set. The baseline characteristics of the patients in the training and validation sets are shown in Table 1. The baseline characteristics were similar between the two sets, except for sex. The percentage of males in the training set was higher than that of the validation set $(81.3 \%$ vs. $76.4 \%, P=0.012)$.

During follow-up, MACE occurred in 201 (15.1\%) cases in the training data set but not in 1123 cases. For the training set, after 6 months, 1 year and 4 years, the MACE rates were $3.1 \%, 3.8 \%$ and $14.0 \%$, respectively. For the validation set, MACE occurred in 96 (14.5\%) cases but not in 566. The MACE rates in the validation set 6 months, 1 year and 4 years later were $3.9 \%, 4.1 \%$ and $13.4 \%$, respectively. The $\chi^{2}$ test showed no significant differences between the two groups $(P>0.05)$ (Table 1$)$.

\section{Development of the multivariate prognostic nomogram}

According to the univariate Cox regression analysis, 15 candidate clinical variables were found to meet the threshold of $P<0.05$ (Table 2). The multivariate Cox regression analysis indicated that age, LAD stenosis, RCA stenosis, lactate, BNP and LVEF were significant independent predictors of the MACE rate in the training set $(P<0.05)$. These predictors were used to construct the prediction model (Fig. 1). Each predictor corresponded to a specific point by drawing the straight line upwards to the point axis. Scores for each variable were summed and located on the "Total Points" axis. Finally, a vertical line was drawn straight down from the plotted total point axis to the probability axis to locate the likelihood of MACE.

\section{Assessment of the nomogram's performance}

In the training set, the 6-month area under the ROC curve (AUC) was 0.712 (95\% CI 0.621-0.803) for the model, the 1-year AUC was 0.741 (95\% CI 0.665-0.817), and the 4-year AUC was 0.762 (95\% CI 0.692-0.831), indicating excellent discrimination (Table 2). The calibration of predictions from the model was satisfactory, as assessed by comparison of prediction by nomogram to the actual MACE rate across quartiles of risk, as shown in Fig. 2a-c.

\section{Validation of the nomogram}

In the validation set, the AUC at 6 months was 0.811 (95\% CI $0.730-0.891$ ), the 1-year AUC was $0.818(95 \%$ CI $0.739,0.897)$, and the 4-year AUC was 0.724 (95\% CI 0.631-0.816) (Table 3). The favourable calibration of the nomogram was also confirmed in the validation set (Fig. 2d-f).

\section{Comparing the performance of the newly developed risk score with existing risk scores}

In the training and validation sets, we compared the tdROCs of the nomogram with the CADILLAC score and GRACE score. The results showed that the discrimination of the nomogram was most favourable (Table 3; Fig. 3). 
Table 1 Baseline demographics and clinical characteristics of patients in the training set and validation set

\begin{tabular}{|c|c|c|c|}
\hline Variables & Training set $(\mathrm{N}=1324)$ & Validation set $(\mathrm{N}=662)$ & $P$ value \\
\hline \multicolumn{4}{|l|}{ Discrete variables } \\
\hline Sex & & & 0.012 \\
\hline Men (\%) & $1076(81.3)$ & $506(76.4)$ & \\
\hline Women (\%) & $248(18.7)$ & $156(23.6)$ & \\
\hline \multicolumn{2}{|l|}{ Three-vessel coronary artery disease } & & 0.648 \\
\hline Yes (\%) & $375(28.3)$ & $194(29.3)$ & \\
\hline No (\%) & $949(71.7)$ & $468(70.7)$ & \\
\hline \multicolumn{2}{|l|}{ LAD stenosis ( $\geq 50 \%)$} & & 0.346 \\
\hline Yes (\%) & $1044(78.9)$ & $534(80.7)$ & \\
\hline No (\%) & $280(21.1)$ & $128(19.3)$ & \\
\hline \multicolumn{2}{|l|}{ LCX stenosis ( $\geq 50 \%)$} & & 0.775 \\
\hline Yes (\%) & $639(48.3)$ & $315(47.6)$ & \\
\hline No (\%) & $685(51.7)$ & $347(52.4)$ & \\
\hline \multicolumn{2}{|l|}{ RCA stenosis ( $\geq 50 \%)$} & & 0.286 \\
\hline Yes (\%) & $777(58.7)$ & $405(61.2)$ & \\
\hline No (\%) & $547(41.3)$ & $257(38.8)$ & \\
\hline \multicolumn{2}{|l|}{ Hypertension } & & 0.773 \\
\hline Yes (\%) & $741(56.0)$ & $375(56.6)$ & \\
\hline No (\%) & $583(44.0)$ & $287(43.4)$ & \\
\hline \multicolumn{2}{|l|}{ Diabetes } & & 0.564 \\
\hline Yes (\%) & $293(22.1)$ & $139(21.0)$ & \\
\hline No (\%) & $1031(77.9)$ & $523(79.0)$ & \\
\hline \multicolumn{2}{|l|}{ Peripheral artery stenosis } & & 0.818 \\
\hline Yes (\%) & $290(21.9)$ & $148(22.4)$ & \\
\hline No (\%) & $1034(78.1)$ & $514(77.6)$ & \\
\hline \multicolumn{2}{|l|}{ Atrial fibrillation } & & 0.900 \\
\hline Yes (\%) & $90(6.8)$ & $46(6.9)$ & \\
\hline No (\%) & $1234(93.2)$ & $616(93.1)$ & \\
\hline \multicolumn{2}{|l|}{ Previous stroke } & & 0.275 \\
\hline Yes (\%) & $104(7.9)$ & $43(6.5)$ & \\
\hline No (\%) & $1220(92.1)$ & $619(93.5)$ & \\
\hline \multicolumn{2}{|l|}{ Kidney disease } & & 0.695 \\
\hline Yes (\%) & $55(4.2)$ & $30(4.5)$ & \\
\hline No (\%) & $1269(95.8)$ & $632(95.5)$ & \\
\hline \multicolumn{2}{|l|}{ Killip class } & & 0.356 \\
\hline I (\%) & $989(74.7)$ & $485(73.3)$ & \\
\hline \|l (\%) & $187(14.1)$ & $91(13.7)$ & \\
\hline III (\%) & $52(3.9)$ & $23(3.5)$ & \\
\hline IV (\%) & $96(7.3)$ & $63(9.5)$ & \\
\hline \multicolumn{2}{|l|}{ TIMI flow grades } & & 0.190 \\
\hline I (\%) & $91(6.9)$ & $56(8.5)$ & \\
\hline \| (\%) & $12(0.9)$ & $11(1.7)$ & \\
\hline ||I (\%) & $45(3.4)$ & $17(2.6)$ & \\
\hline IV (\%) & $1176(88.8)$ & $578(87.3)$ & \\
\hline \multicolumn{2}{|l|}{ Previous cardiac arrest } & & 0.183 \\
\hline Yes (\%) & $58(4.4)$ & $38(5.7)$ & \\
\hline No (\%) & 1266 (95.6) & $624(94.3)$ & \\
\hline \multicolumn{4}{|l|}{ Continuous variables } \\
\hline Age, year & $64.0(54.0,73.0)$ & $64.0(53.0,73.0)$ & 0.8513 \\
\hline
\end{tabular}


Table 1 (continued)

\begin{tabular}{lccc}
\hline Variables & Training set $(\mathbf{N}=\mathbf{1 3 2 4})$ & Validation set $(\mathbf{N}=\mathbf{6 6 2})$ & $\boldsymbol{P}$ value \\
\hline Lactate, $\mathrm{mmol} / \mathrm{L}$ & $2.80(2.20,3.70)$ & $2.80(2.10,3.70)$ & 0.687 \\
BNP, pg/mL & $277.0(103.0,671.5)$ & $270.5(109.0,755.0)$ & 0.6686 \\
Uric acid, $\mu \mathrm{mol} / \mathrm{L}$ & $361.0(300.0,438.5)$ & $369.0(305.0,447.0)$ & 0.0871 \\
LVEF, \% & $48.0(43.0,55.8)$ & $49.0(43.0,55.0)$ & 0.9864 \\
EGFR, $\mathrm{mL} / \mathrm{min} / 1.73 \mathrm{~m}^{2}$ & $82.8(61.0,100.8)$ & $83.7(58.8,100.8)$ & 0.6192 \\
Creatinine, $\mu \mathrm{mol} / \mathrm{L}$ & $83.0(71.0,102.0)$ & $82.0(70.0,105.0)$ & 0.4397 \\
Haemoglobin, g/L & $133.0(120.0,144.0)$ & $132.0(119.0,143.0)$ & 0.5253 \\
MACE rate & & & \\
6-month (\%) & $42(3.1)$ & $26(3.9)$ & 0.3763 \\
1-year (\%) & $50(3.8)$ & $27(4.1)$ & 0.7573 \\
4-year (\%) & $186(14.0)$ & $89(13.4)$ & 0.7132 \\
\hline
\end{tabular}

$B N P$ brain natriuretic peptide, EGFR estimated glomerular filtration rate, $L A D$ left anterior descending branch, $L C X$ left circumflex artery, LVEF left ventricular ejection fraction, MACE major adverse cardiovascular events, RCA right coronary artery

Table 2 Univariate and multivariable Cox hazards analysis of the training cohort

\begin{tabular}{|c|c|c|c|c|c|}
\hline \multirow[t]{2}{*}{ Variables } & \multicolumn{2}{|l|}{ Univariate } & \multicolumn{2}{|l|}{ Multivariate } & \multirow[t]{2}{*}{ Score } \\
\hline & $\mathrm{HR}(95 \% \mathrm{Cl})$ & $P$ value & $\mathrm{HR}(95 \% \mathrm{Cl})$ & $P$ value & \\
\hline \multicolumn{6}{|l|}{ Statistically significant factors } \\
\hline \multicolumn{6}{|l|}{ Age, year } \\
\hline$<65$ & Ref & Ref & Ref & Ref & 0 \\
\hline $65-75$ & $1.636(1.157-2.314)$ & 0.005 & $1.295(0.909-1.847)$ & 0.153 & 31 \\
\hline$\geq 75$ & $2.807(2.015-3.910)$ & $<0.001$ & $1.866(1.307-2.663)$ & 0.001 & 75 \\
\hline LAD stenosis $\geq 50 \%$ & $2.192(1.445,3.327)$ & $<0.001$ & $1.909(1.247-2.925)$ & 0.003 & 78 \\
\hline RCA stenosis $\geq 50 \%$ & $1.969(1.444,2.684)$ & $<0.001$ & $1.854(1.350-2.545)$ & $<0.001$ & 74 \\
\hline Lactate $\geq 2 \mathrm{mmol} / \mathrm{L}$ & $1.604(1.096,2.347)$ & 0.015 & $1.555(1.051-2.299)$ & 0.027 & 53 \\
\hline \multicolumn{6}{|l|}{$\mathrm{BNP}, \mathrm{pg} / \mathrm{mL}$} \\
\hline$<500$ & Ref & Ref & Ref & Ref & 0 \\
\hline $500-1000$ & $1.467(1.002,2.150)$ & 0.049 & $1.105(0.744-1.642)$ & 0.621 & 12 \\
\hline$\geq 1000$ & $3.506(2.567,4.789)$ & $<0.001$ & $2.284(1.620-3.219)$ & $<0.001$ & 100 \\
\hline LVEF $<40 \%$ & $2.138(1.585,2.885)$ & $<0.001$ & $1.607(1.167-2.211)$ & 0.004 & 57 \\
\hline Men & $0.508(0.375,0.689)$ & $<0.001$ & & & \\
\hline LCX stenosis $\geq 50 \%$ & $1.394(1.051,1.848)$ & 0.021 & & & \\
\hline Hypertension & $1.523(1.137,2.040)$ & 0.005 & & & \\
\hline Diabetes & $1.310(0.952,1.803)$ & 0.097 & & & \\
\hline Atrial fibrillation & $1.841(1.223,2.771)$ & 0.003 & & & \\
\hline Kidney disease & $2.284(1.367,3.814)$ & 0.002 & & & \\
\hline $\mathrm{EGFR}<60 \mathrm{~mL} / \mathrm{min} / 1.73 \mathrm{~m}^{2}$ & $2.149(1.618,2.855)$ & $<0.001$ & & & \\
\hline Creatinine $>186 \mu \mathrm{mol} / \mathrm{L}$ & $2.402(1.566,3.684)$ & $<0.001$ & & & \\
\hline Haemoglobin < $120 \mathrm{~g} / \mathrm{L}$ & $1.831(1.370,2.448)$ & $<0.001$ & & & \\
\hline \multicolumn{6}{|c|}{ Statistically non-significant factors } \\
\hline Peripheral artery stenosis & $1.290(0.928,1.793)$ & 0.129 & & & \\
\hline Previous stroke & $1.419(0.924,2.179)$ & 0.109 & & & \\
\hline Previous cardiac arrest & $1.193(0.611,2.331)$ & 0.605 & & & \\
\hline Uric acid, $\mu \mathrm{mol} / \mathrm{L}$ & $1.310(0.926,1.854)$ & 0.128 & & & \\
\hline
\end{tabular}




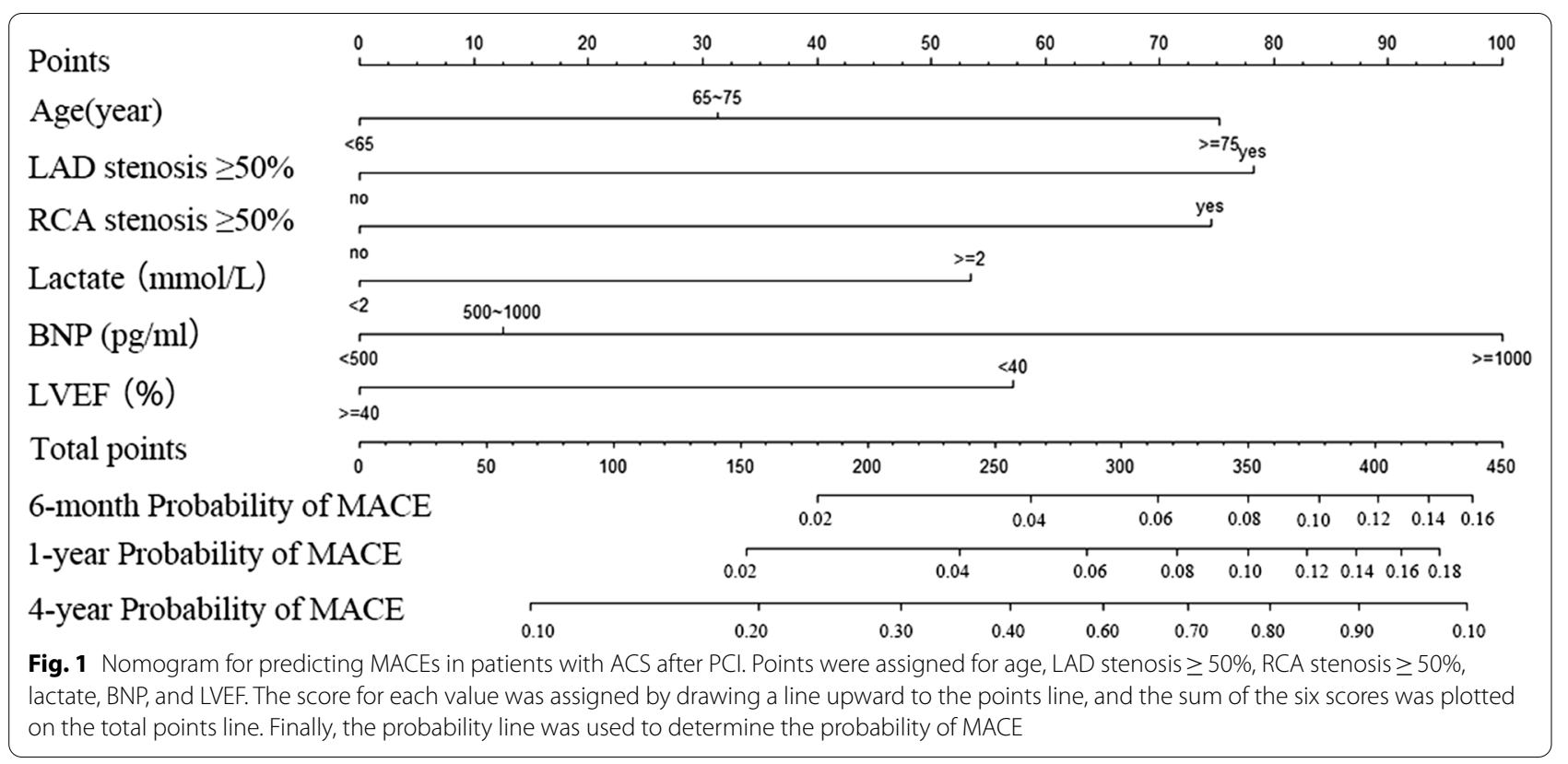

\section{Performance of the prognostic nomogram in stratifying risk}

In the training set with an endpoint time of 4 years, the total prognostic scores calculated by the nomogram were categorized into two risk groups to predict MACE: 'lowrisk' (score $\leq 285.1$ ) and 'high-risk' (score > 285.1) based on the cut-off value calculated using X-tile software [28] (Fig. 4).

The Kaplan-Meier curves for both sets clearly showed that the nomogram was stable in differentiating between high-risk and low-risk patients (Fig. 5). The HR for the 'high-risk' category was found to be 4.11 (95\% CI 3.085.49) compared to the 'low-risk' category in the training set and 4.01 (95\% CI 2.68-6.00) in the validation set.

\section{Discussion}

Our results confirmed that several demographic and clinical characteristics reported from previous models developed from other databases can be used to construct a simple model for prognostic evaluation. The 6 most important factors-lactate level, age, LAD stenosis, RCA stenosis, BNP level, and LVEF-contained most of the prognostic information and were incorporated into the nomogram. To our knowledge, this nomogram is the first clinical prediction model incorporating lactate for predicting the long-term risk of MACEs among patients with ACS after PCI. Nomograms are evidence-based and fully personalized tools to guide clinical decision-making and provide patient-friendly, accurate and repeatable predictions without the need for computer software to interpret [30]. Risk stratification is important in determining which medications and revascularization should be used. In addition, the prediction contributes to the development of health care and clinical guidelines for ACS.

Lactate, as an easily and quickly assessed metabolite, has been studied over time in acute cardiac patients to evaluate its prognostic ability [19]. A meta-analysis showed a greater reduction in lactate concentrations in survivors than in non-survivors, whether following cardiac surgery, cardiogenic shock, or cardiac arrest [31]. Harjola et al. found that lactate level $(>2 \mathrm{mmol} / \mathrm{L})$ was independently associated with increased shortterm mortality for patients with cardiogenic shock [32]. For patients with STEMI, higher lactate levels were independently associated with 30-day mortality and overall adverse reactions to PCI (in particular, lactate $\geq 1.8 \mathrm{mmol} / \mathrm{L}$ ) [33]. Marashly et al. found that for patients with cardiogenic shock secondary to acute coronary syndrome, lactate $\geq 2.5 \mathrm{mmol} / \mathrm{L}$ could independently predict 30-day all-cause mortality and then established an ACS-MCS score [34]. Ruling out cardiogenic shock, in 766 patients with STEMI and NSTEMI undergoing coronary artery bypass surgery, lactate was a predictor of 30-day and late mortality [35]. In addition, in a study of 1865 patients with ACS, elevated lactate levels $(\geq 1.8 \mathrm{mmol} / \mathrm{L})$ at admission were an independent predictor of 30-day and 180-day all-cause mortality [18]. Lactate is an important fuel for the stressed heart and is produced by the dehydrogenation of pyruvate, which is synthesized from glycolysis [36, 37]. In a 


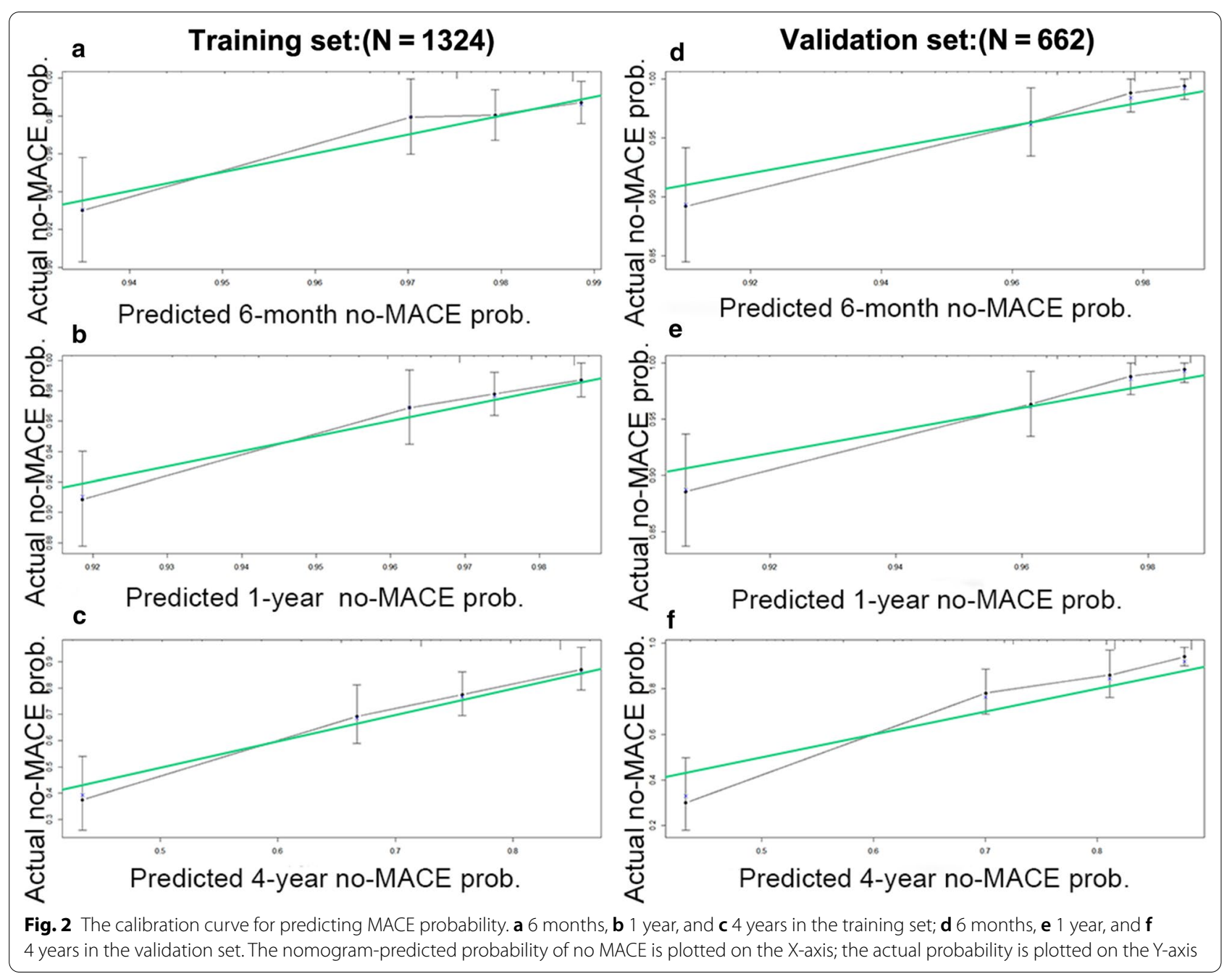

Table 3 Comparisons of AUCs of the risk scores to predict MACEs

\begin{tabular}{|c|c|c|c|c|c|c|c|}
\hline \multirow[t]{2}{*}{ Time } & \multirow[t]{2}{*}{ Risk scores } & \multicolumn{3}{|c|}{ Training set } & \multicolumn{3}{|c|}{ Validation set } \\
\hline & & AUC & $95 \% \mathrm{Cl}$ & $P$ value & AUC & $95 \% \mathrm{Cl}$ & $P$ value \\
\hline \multirow[t]{3}{*}{6 months } & Nomogram & 0.712 & $0.621-0.803$ & Ref & 0.811 & $0.730-0.891$ & Ref \\
\hline & CADILLAC score & 0.674 & $0.582-0.766$ & 0.2840 & 0.715 & $0.605-0.825$ & 0.0044 \\
\hline & GRACE score & 0.653 & $0.556-0.751$ & 0.1519 & 0.75 & $0.659-0.842$ & 0.0351 \\
\hline \multirow[t]{3}{*}{1 year } & Nomogram & 0.741 & $0.665-0.817$ & Ref & 0.818 & $0.739-0.897$ & Ref \\
\hline & CADILLAC score & 0.699 & $0.622-0.775$ & 0.1670 & 0.725 & $0.617-0.833$ & 0.0043 \\
\hline & GRACE score & 0.662 & $0.578-0.746$ & 0.0360 & 0.761 & $0.672-0.850$ & 0.0390 \\
\hline \multirow[t]{3}{*}{4 years } & Nomogram & 0.762 & $0.692-0.831$ & Ref & 0.724 & $0.631-0.816$ & Ref \\
\hline & CADILLAC score & 0.572 & $0.496-0.648$ & $<0.0001$ & 0.629 & $0.534-0.724$ & 0.0024 \\
\hline & GRACE score & 0.629 & $0.549-0.710$ & 0.0003 & 0.622 & $0.522-0.722$ & 0.0209 \\
\hline
\end{tabular}




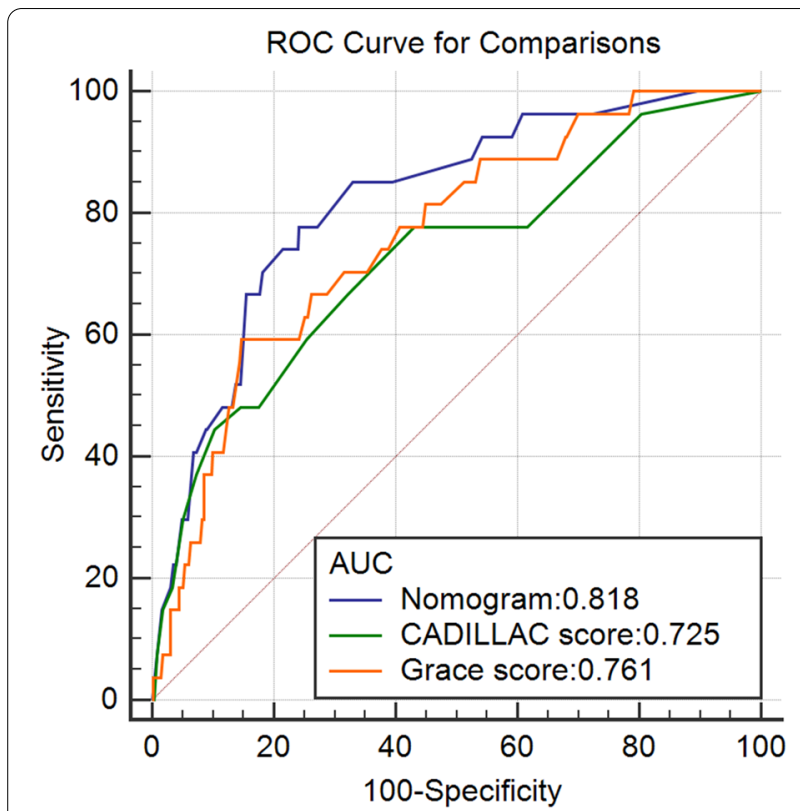

Fig. 3 Time-dependent ROC curve (tdROC) for the nomogram, CADILLAC score and GRACE score. Performance comparison was assessed between the nomogram, CADILLAC score and GRACE score by calculating the area under the ROC curves in the validation set for 1-year MACE. CADILLAC the Controlled Abciximab and Device Investigation to Lower Late Angioplasty Complications study, GRACE the Global Registry of Acute Coronary Events, ROC receiver operating characteristics

normal heart at rest, $\beta$-oxidation of fatty acids provides approximately $60-90 \%$ of energy, while pyruvate produces $10-40 \%$ [38]. During exercise, the uptake and use of lactate in the myocardium increases, as does the stimulation of $\beta$-adrenergic stimulation and shock [39]. Hyperlactatemia can be seen as part of the stress response, including increased metabolic rate, sympathetic nervous system activation, accelerated glycolysis, and improved bioenergy supply [19]. Hyperlactate after ACS may be caused by hypoxia following haemodynamic disorders or by catecholamine-induced aerobic glycolysis in response to stress $[39,40]$. These studies suggest that lactate may play an important role in the course of ACS. To the best of our knowledge, however, there has been no risk prediction tool for MACEs integrating lactate to date. Therefore, a well-performed risk prediction model incorporating lactate is urgently needed. It must be acknowledged that certain drugs (e.g., metformin, sodium bicarbonate), preoperatively sustained fasting periods with volume depletion, and even hypertension could have contributed to changes in lactate levels, which could interfere with this evaluation [35]. Unfortunately, we did not calculate lactate clearance, which has been reported to be more reliable on clinical grounds than lactate for risk stratification in different critical illness conditions [41-43].

For the other five variables, TIMI risk score indicated prior coronary stenosis of $50 \%$ or more as an independent predictor for the primary end point (all-cause mortality, MI, or urgent revascularization) occurred by 14 days [16]. In a study of 6755 patients after PCI, Iqbal et al. found that for patients with multivessel disease, untreated proximal LAD and RCA (stenosis $>70 \%$ ) w ere associated with increased mortality [44]. BNP level was a strong independent predictor of short-term postoperative mortality [45]. Grabowski et al. improved their model's predictive power by adding BNP to the Killip class and TIMI flow grades [46]. A possible explanation is that an elevated BNP level reflects a larger infarct size and progressive left ventricular remodelling, thus more

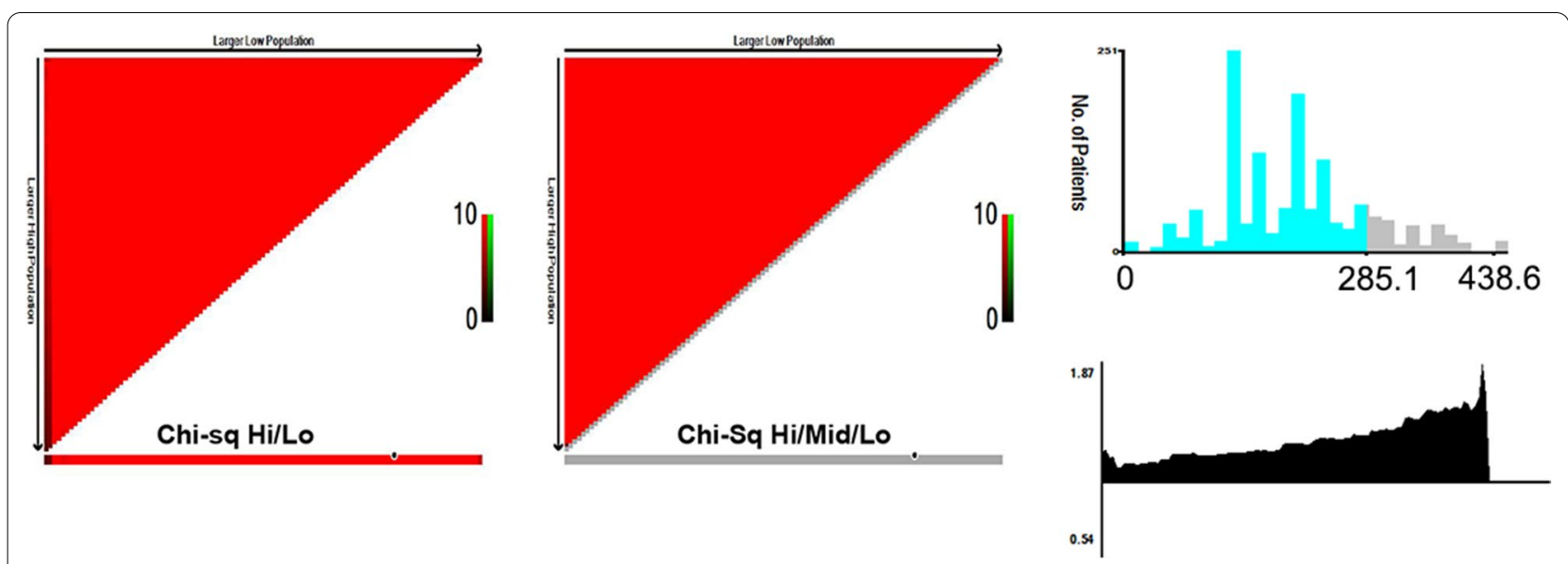

Fig. $4 X$-tile analysis of the total risk score in the training set and cut-off value. The optimal cut-off value for the total risk score was 285.1 $\left(X^{2}=99.0394, P<0.001\right)$ 

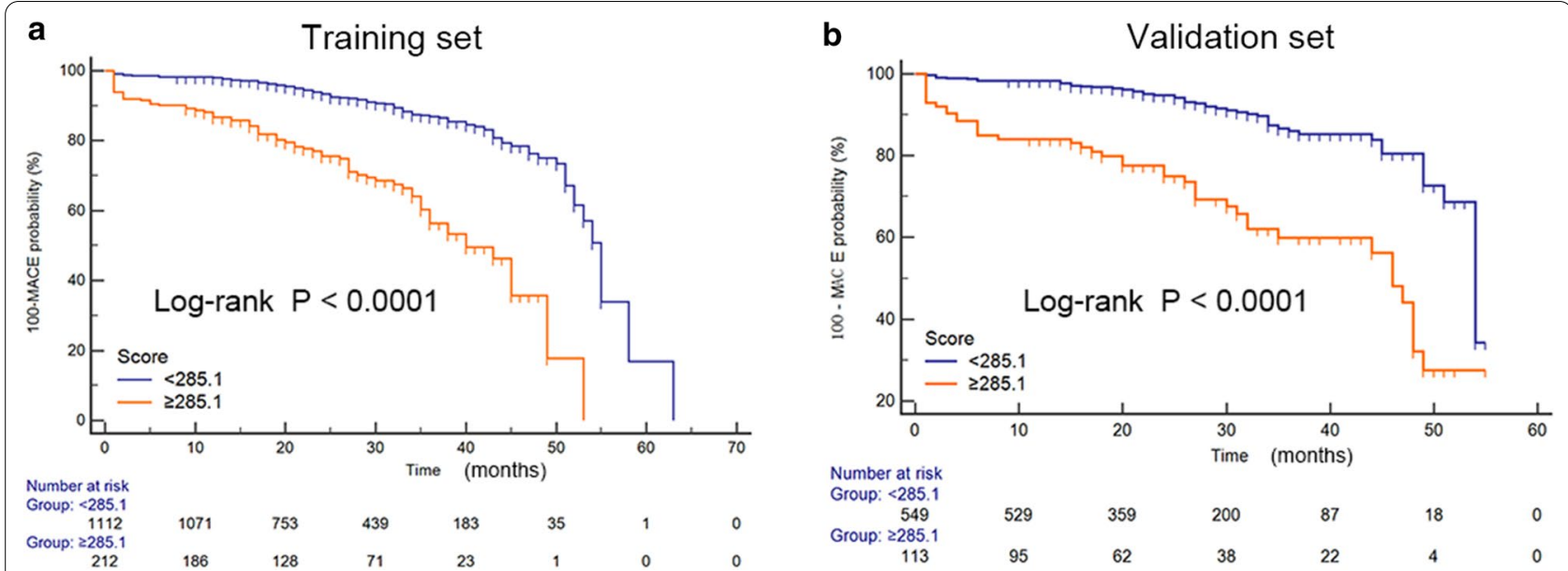

Fig. 5 Kaplan-Meier survival curves in the training (a) and validation sets (b), stratified by the nomogram ('high-risk' [score $\geq 285.1]$ and 'low-risk' [score $<285.1)$ )

obviously reflecting the degree of cardiac insufficiency [47]. Similar to BNP, LVEF also serves as a reference index for cardiac function to supply important prognostic information and should be included in approaches for stratifying risk after myocardial infarction $[48,49]$ Many studies have reported that age is a significant risk factor for clinical events (cardiac death, target vessel myocardial infarction, and clinically driven target vessel revascularization) after PCI $[50,51]$. The predictive ability of simple age cut-off points of 65 and 75 are similar to that of a more complex model with age as a continuous variable [16]. To overcome or avoid the limitations of a single predictor and achieve high prediction accuracy, we combined six detected predictors into this model. Because of dynamic variations, the nomogram did not include clinical symptoms and signs, such as Killip class, heart rate, and systolic blood pressure, which are significantly associated with ACS mortality [7, 8, 14, 16]; Killip class may result in information bias by the judgement error of the clinician's supervisor. Nomograms are easy to recall and clinically useful.

The model had adequate discrimination and calibration power in the training set $(\mathrm{AUC}=0.712-0.762)$ to predict MACEs and appeared statistically robust in that it was validated in a separate third of the participants (AUC $=0.724-0.818$ ). Discrimination for MACE prediction of the nomogram was superior to GRACE risk score and CADILLAC risk score in both sets, confirming that nomogram was more valuable in predicting MACEs, especially in the long term. The TIMI risk score, published in 2000, predicted the primary end point (all-cause mortality, MI, or severe recurrent ischaemia requiring urgent revascularization) through 14 days after randomization for UA/NSTEMI [52]. The GRACE risk score has been established to predict the risk of death during hospitalization and at 6 months for patients with ACS [7]. To predict 30-day and 1-year mortality risk after PCI for AMI, the PAMI risk score and CADILLAC risk score were established successively $[8,14]$. Several studies have proven that in predicting 30-day and 1-year mortality, the CADILLAC risk score showed slight superiority over GRACE, TIMI, and PAMI risk scores [53-55]. The probable reason is that the CADILLAC risk score emphasizes the importance of LVEF and three-vessel disease [54]. Our nomogram also incorporated these variables. Their predictors, such as heart rate, systolic blood pressure, myocardial enzymes and creatinine, are dynamic. Killip class, postprocedural TIMI flow grade, and ST-segment deviation require the judgement of professional physicians. In addition, previous risk models were derived from Western populations, which limited their application to other populations. In addition, few of the participants were followed up for more than one year.

In regard to the clinical application of the nomogram, we have taken an example of a case of 75 years old (75 points), LAD stenosis $50 \%$ (78 points), RCA stenosis $10 \%$ (0 point), lactate $1 \mathrm{mmol} / \mathrm{L}$ (0 point), BNP $100 \mathrm{pg} / \mathrm{ml}(0$ point) and LVEF $38 \%$ (57 points). The total score was 210 , and the expected MACE rates after 6 months, 1 year and 4 years were $2 \%, 3 \%$ and $30 \%$, respectively. Patients with ACS undergoing PCI can be thus classified into high- and low-risk groups for 4-year MACEs.

The most attractive aspect features of these models are their accuracy, generalizability, and ease of use. The nomogram is an excellent model to span the entire spectrum of ACS. It is based on a relatively unselected group of patients, representing patients seen in general clinical practice. It includes a new variable, lactate level, that is 
stable and easily accessible. In addition, the nomogram has an excellent ability to discriminate risk. In the past, risk scores were mostly based on Western populations, while the population of patients with ACS after PCI in the East, especially in China, was much larger, requiring a specialized prediction model. The nomogram uses the latest clinical data from the past 7 years to reflect the current cardiovascular medical level. Although ACS can be treated in many ways, our study evaluated patient outcomes solely treated with PCI, with fewer uncontrolled variables and more stable clinical events. Unlike traditional risk scores, a follow-up period of up to 4 years is conducive to the evaluation of long-term prognosis.

Limitations also existed in this study. Although lactate has certain predictive ability, the detection time and collection method of lactate are not unified and clear. Some clinical drugs may cause changes in lactate without improving the prognosis. Besides, the role of lactate may not be consistent in a general cohort of ACS patients including STEMI, NSTEMI and UA. Since it clearly indicates those patients with hemodinamic compromise and more probably STEMI patients. Subgroup analyses of STEMI, NSTEMI and UA were not performed for lack of adequate detailed information of all patients, resulting in the prediction performance of the model in this three cohorts not being estimated separately. A multicenter validation study, particularly involving other ethnic groups, is required to confirm the performance of the nomogram before clinical application.

\section{Conclusions}

In conclusion, a novel prognostic nomogram incorporating lactate level and five other easily available and objective variables can serve as an accurate and favourable prognostic prediction of 6-month, 1-year, and 4-year incidence of MACEs among patients with the entire spectrum of ACS after PCI. This information can help clinicians stratify risk for optimal triage and management.

\begin{abstract}
Abbreviations
ACS: Acute coronary syndrome; AMI: Acute myocardial infarction; AUC: Area under the receiver operating characteristic curve; BNP: Brain natriuretic peptide; Cl: Confidence interval; CKD-EPI: Chronic Kidney Disease Epidemiology Collaboration; EGFR: Estimated glomerular filtration rate; HB: Haemoglobin; HR: Hazard ratio; LAD: Left anterior descending branch; LCX: Left circumflex artery; LVEF: Left ventricular ejection fraction; MACE: Major adverse cardiovascular events; NSTE-ACS: Non-ST-segment elevation acute coronary syndrome; NSTEMI: Non-ST-segment elevation myocardial infarction; PCI: Percutaneous coronary intervention; RCA: Right coronary artery; ROC: Receiver operating characteristic; STEMI: ST-segment elevation myocardial infarction; tdROC: Time-dependent receiver operating characteristic curve; UA: Unstable angina.
\end{abstract}

\section{Acknowledgements}

We would like to thank the investigators of the First Affiliated Hospital of Wenzhou Medical University and participants for their contributions.

\section{Authors' contributions}

SK: conceptualized and designed the study, collected the clinical data, performed statistical analysis, and drafted the manuscript and figures. CC: collected the clinical data. GZ: collected the clinical data. HY: collected the clinical data and follow-up data. JL: searched the relevant literature. HY: edited the manuscript. XW: statistical analysis. XQ: data curation. XZ: study conceptualization and design. YL: collected the clinical data. HZ: conceptualized the study and designed and reviewed and edited the manuscript. All authors read and approved the final manuscript.

\section{Funding}

This research was funded by the National Natural Science Foundation of China (No. 81873468).

\section{Availability of data and materials}

The datasets used and/or analysed during the current study are available from the corresponding author upon reasonable request.

\section{Declarations}

Ethics approval and consent to participate

The prospective study was approved by the Ethics Committee of the First Affiliated Hospital of Wenzhou Medical University. All study subjects provided informed consent.

\section{Consent for publication}

Not applicable.

\section{Competing interests}

The authors declare that they have no competing interests.

\section{Author details}

'Department of Cardiology, The First Affiliated Hospital of Wenzhou Medical University, Wenzhou 325000, Zhejiang, China. ${ }^{2}$ Cardiac Interventional Center, The First Affiliated Hospital of Wenzhou Medical University, Wenzhou 325000, Zhejiang, China. ${ }^{3}$ Affiliated Jinhua Hospital, Zhejiang University School of Medicine, Jinghua 321000, Zhejiang, China. ${ }^{4}$ The First Clinical Medical College of Wenzhou Medical University, Wenzhou Medical University, Wenzhou 325000, Zhejiang, China.

Received: 12 January 2021 Accepted: 5 May 2021

Published online: 22 May 2021

\section{References}

1. Global health estimates 2016: deaths by cause, age, sex, by country and by region, 2000-2016, 2018. https://www.who.int/healthinfo/global_ burden_disease/en/.

2. Thygesen K, Alpert JS, Jaffe AS, Chaitman BR, Bax JJ, Morrow DA, White HD. Fourth Universal Definition of Myocardial Infarction (2018). J Am Coll Cardiol. 2018;72(18):2231-64.

3. Keeley EC, Boura JA, Grines CL. Primary angioplasty versus intravenous thrombolytic therapy for acute myocardial infarction: a quantitative review of 23 randomised trials. Lancet (London, England). 2003;361(9351):13-20.

4. Zijlstra F, Hoorntje JC, de Boer MJ, Reiffers S, Miedema K, Ottervanger JP, van't Hof AW, Suryapranata H. Long-term benefit of primary angioplasty as compared with thrombolytic therapy for acute myocardial infarction. N Engl J Med. 1999;341(19):1413-9.

5. Park D, Ahn J, Park H, Yun S, Kang D, Lee P, Kim Y, Lim D, Rha S, Park G, et al. Ten-year outcomes after drug-eluting stents versus coronary artery bypass grafting for left main coronary disease: extended follow-up of the PRECOMBAT trial. Circulation. 2020;141(18):1437-46.

6. Sud M, Han L, Koh M, Abdel-Qadir H, Austin P, Farkouh M, Godoy L, Lawler P, Udell J, Wijeysundera $\mathrm{H}$, et al. Low-density lipoprotein cholesterol and adverse cardiovascular events after percutaneous coronary intervention. J Am Coll Cardiol. 2020;76(12):1440-50.

7. Granger CB, Goldberg RJ, Dabbous O, Pieper KS, Eagle KA, Cannon CP, Van de Werf F, Avezum A, Goodman SG, Flather MD, et al. Predictors of 
hospital mortality in the global registry of acute coronary events. Arch Intern Med. 2003;163(19):2345-53.

8. Halkin A, Singh M, Nikolsky E, Grines CL, Tcheng JE, Garcia E, Cox DA, Turco M, Stuckey TD, Na Y, et al. Prediction of mortality after primary percutaneous coronary intervention for acute myocardial infarction: the CADILLAC risk score. J Am Coll Cardiol. 2005;45(9):1397-405.

9. Morrow DA, Antman EM, Charlesworth A, Cairns R, Murphy SA, de Lemos JA, Giugliano RP, McCabe CH, Braunwald E. TIMI risk score for ST-elevation myocardial infarction: a convenient, bedside, clinical score for risk assessment at presentation: an intravenous nPA for treatment of infarcting myocardium early II trial substudy. Circulation. 2000;102(17):2031-7.

10. Morrow DA, Antman EM, Giugliano RP, Cairns R, Charlesworth A, Murphy $\mathrm{SA}$, de Lemos JA, McCabe $\mathrm{CH}$, Braunwald $\mathrm{E}$. A simple risk index for rapid initial triage of patients with ST-elevation myocardial infarction: an InTIME II substudy. Lancet (London, England). 2001;358(9293):1571-5.

11. Dorsch MF, Lawrance RA, Sapsford RJ, Oldham J, Greenwood DC, Jackson BM, Morrell C, Ball SG, Robinson MB, Hall AS. A simple benchmark for evaluating quality of care of patients following acute myocardial infarction. Heart. 2001;86(2):150-4.

12. Vernon ST, Coffey S, D'Souza M, Chow CK, Kilian J, Hyun K, Shaw JA, Adams M, Roberts-Thomson P, Brieger D, et al. ST-segment-elevation myocardial infarction (STEMI) patients without standard modifiable cardiovascular risk factors-how common are they, and what are their outcomes? J Am Heart Assoc. 2019;8(21):e013296-e013296.

13. Huynh T, Kouz S, Yan AT, Danchin N, O'Loughlin J, Schampaert E, Yan RT, Rinfret S, Tardif JC, Eisenberg MJ, et al. Canada Acute Coronary Syndrome Risk Score: a new risk score for early prognostication in acute coronary syndromes. Am Heart J. 2013;166(1):58-63.

14. Addala S, Grines CL, Dixon SR, Stone GW, Boura JA, Ochoa AB, Pellizzon G, O'Neill WW, Kahn JK. Predicting mortality in patients with ST-elevation myocardial infarction treated with primary percutaneous coronary intervention (PAMl risk score). Am J Cardiol. 2004;93(5):629-32.

15. Fox KA, Dabbous OH, Goldberg RJ, Pieper KS, Eagle KA, Van de Werf F, Avezum A, Goodman SG, Flather MD, Anderson FA Jr, et al. Prediction of risk of death and myocardial infarction in the six months after presentation with acute coronary syndrome: prospective multinational observational study (GRACE). BMJ (Clin Res Ed). 2006;333(7578):1091.

16. Antman EM, Cohen M, Bernink PJ, McCabe CH, Horacek T, Papuchis G, Mautner B, Corbalan R, Radley D, Braunwald E. The TIMl risk score for unstable angina/non-ST elevation MI: a method for prognostication and therapeutic decision making. JAMA. 2000;284(7):835-42.

17. Amsterdam EA, Wenger NK, Brindis RG, Jr CD, Ganiats TG, Jr HD, Jaffe AS, Jneid H, Kelly RF, Kontos MC: 2014 AHA/ACC guideline for the management of patients with non-ST-elevation acute coronary syndromes: a report of the American College of Cardiology/American Heart Association Task Force on Practice Guidelines. Duke University Press; 2014.

18. Liang D, Zhou X, Hong X, Feng X, Shan P, Xie Q, Xu T, Cai M, Zhou J, Wang $S$, et al. Association between admission lactate levels and mortality in patients with acute coronary syndrome: a retrospective cohort study. Coron Artery Dis. 2019;30(1):26-32.

19. Lazzeri C, Valente S, Chiostri M, Gensini G. Clinical significance of lactate in acute cardiac patients. World J Cardiol. 2015;7(8):483-9.

20. Porto I, Mattesini A, D'Amario D, Sorini Dini C, Della Bona R, Scicchitano M, Vergallo R, Martellini A, Caporusso S, Trani C, et al. Blood lactate predicts survival after percutaneous implantation of extracorporeal life support for refractory cardiac arrest or cardiogenic shock complicating acute coronary syndrome: insights from the CareGem registry. Intern Emerg Med. 2021;16(2):463-470.

21. Rigamonti F, Montecucco F, Boroli F, Rey F, Gencer B, Cikirikcioglu M, Reverdin S, Carbone F, Noble S, Roffi M, et al. The peak of blood lactate during the first $24 \mathrm{~h}$ predicts mortality in acute coronary syndrome patients under extracorporeal membrane oxygenation. Int J Cardiol. 2016;221:741-5.

22. O'Gara PT, Kushner FG, Ascheim DD, Casey DE, Chung MK, de Lemos JA, Ettinger SM, Fang JC, Fesmire FM, Franklin BA, et al. 2013 ACCF/AHA guideline for the management of ST-elevation myocardial infarction: a report of the American College of Cardiology Foundation/American Heart Association Task Force on Practice Guidelines. J Am Coll Cardiol. 2013;61(4):e78-140.

23. Amsterdam EA, Wenger NK, Brindis RG, Casey DE, Ganiats TG, Holmes DR, Jaffe AS, Jneid H, Kelly RF, Kontos MC, et al. 2014 AHA/ACC guideline for the management of patients with non-ST-elevation acute coronary syndromes: a report of the American College of Cardiology/American Heart Association Task Force on Practice Guidelines. J Am Coll Cardiol. 2014;64(24):e139-228.

24. Levey AS, Stevens LA, Schmid CH, Zhang YL, Castro AF 3rd, Feldman HI, Kusek JW, Eggers P, Van Lente F, Greene T, et al. A new equation to estimate glomerular filtration rate. Ann Intern Med. 2009;150(9):604-612.

25. Schwaiger JP, Reinstadler SJ, Tiller C, Holzknecht M, Reindl M, Mayr A, Graziadei I, Müller S, Metzler B, Klug G. Baseline LV ejection fraction by cardiac magnetic resonance and $2 \mathrm{D}$ echocardiography after ST-elevation myocardial infarction-influence of infarct location and prognostic impact. Eur Radiol. 2020;30(1):663-71.

26. Møller JE, Hillis GS, Oh JK, Reeder GS, Gersh BJ, Pellikka PA. Wall motion score index and ejection fraction for risk stratification after acute myocardial infarction. Am Heart J. 2006;151(2):419-25.

27. Chambless LE, Diao G. Estimation of time-dependent area under the ROC curve for long-term risk prediction. Stat Med. 2006;25(20):3474-86.

28. Shi K-Q, Cai Y-J, Lin Z, Dong J-Z, Wu J-M, Wang X-D, Song M, Wang Y-Q, Chen Y-P. Development and validation of a prognostic nomogram for acute-on-chronic hepatitis B liver failure. J Gastroenterol Hepatol. 2017;32(2):497-505.

29. Camp RL, Dolled-Filhart M, Rimm DL. X-Tile. A new bio-informatics tool for biomarker assessment and outcome-based cut-point optimization. Clin Cancer Res. 2004;10(21):7252-9.

30. lasonos A, Schrag D, Raj GV, Panageas KS. How to build and interpret a nomogram for cancer prognosis. J Clin Oncol. 2008;26(8):1364-70.

31. Vincent $J L$, Quintairos ESA, Couto L Jr, Taccone FS. The value of blood lactate kinetics in critically ill patients: a systematic review. Crit Care (Lond, England). 2016;20(1):257.

32. Harjola VP, Lassus J, Sionis A, Køber L, Tarvasmäki T, Spinar J, Parissis J, Banaszewski M, Silva-Cardoso J, Carubelli V, et al. Clinical picture and risk prediction of short-term mortality in cardiogenic shock. Eur J Heart Fail. 2015;17(5):501-9.

33. Vermeulen RP, Hoekstra M, Nijsten MW, van der Horst IC, van Pelt LJ, Jessurun GA, Jaarsma T, Zijlstra F, van den Heuvel AF. Clinical correlates of arterial lactate levels in patients with ST-segment elevation myocardial infarction at admission: a descriptive study. Crit Care (London, England). 2010;14(5):R164.

34. Marashly Q, Taleb I, Kyriakopoulos CP, Dranow E, Jones TL, Tandar A, Overton SD, Tonna JE, Stoddard K, Wever-Pinzon O, et al. Predicting mortality in cardiogenic shock secondary to ACS requiring short-term mechanical circulatory support: the ACS-MCS score. Catheter Cardiovasc Interv. 2021. https://doi.org/10.1002/ccd.29581.

35. Grothusen C, Friedrich C, Loehr J, Meinert J, Ohnewald E, Ulbricht U, Attmann T, Haneya A, Huenges K, Freitag-Wolf S, et al. Outcome of stable patients with acute myocardial infarction and coronary artery bypass surgery within 48 hours: a single-center, retrospective experience. J Am Heart Assoc. 2017;6(10):e005498.

36. Kubiak GM, Tomasik AR, Bartus K, Olszanecki R, Ceranowicz P. Lactate in cardiogenic shock_current understanding and clinical implications. J Physiol Pharmacol. 2018;69(1):15-21.

37. Hütter JF, Schweickhardt C, Piper HM, Spieckermann PG. Inhibition of fatty acid oxidation and decrease of oxygen consumption of working rat heart by 4-bromocrotonic acid. J Mol Cell Cardiol. 1984;16(1):105-8.

38. Beadle RM, Frenneaux M. Modification of myocardial substrate utilisation: a new therapeutic paradigm in cardiovascular disease. Heart. 2010;96(11):824-30.

39. Garcia-Alvarez M, Marik P, Bellomo R. Stress hyperlactataemia: present understanding and controversy. Lancet Diabetes Endocrinol. 2014;2(4):339-47.

40. Kraut JA, Madias NE. Lactic acidosis. N Engl J Med. 2014;371(24):2309-19.

41. Abramson D, Scalea T, Hitchcock R, Trooskin S, Henry S, Greenspan J. Lactate clearance and survival following injury. J Trauma. 1993;35(4):584-8.

42. Lindsay A, Xu M, Sessler D, Blackstone E, Bashour C. Lactate clearance time and concentration linked to morbidity and death in cardiac surgical patients. Ann Thorac Surg. 2013;95(2):486-92.

43. Zhang Z, Xu X. Lactate clearance is a useful biomarker for the prediction of all-cause mortality in critically ill patients: a systematic review and meta-analysis*. Crit Care Med. 2014;42(9):2118-25.

44. Iqbal MB, Smith RD, Lane R, Patel N, Mattar W, Kabir T, Panoulas V, Mason M, Dalby MC, Grocott-Mason R, et al. The prognostic significance of 
incomplete revascularization and untreated coronary anatomy following percutaneous coronary intervention: an analysis of 6,755 patients with multivessel disease. Catheter Cardiovasc Interv. 2018;91(7):1229-39.

45. Grabowski M, Filipiak KJ, Karpinski G, Wretowski D, Rdzanek A, Huczek Z, Horszczaruk GJ, Kochman J, Rudowski R, Opolski G. Serum B-type natriuretic peptide levels on admission predict not only short-term death but also angiographic success of procedure in patients with acute ST-elevation myocardial infarction treated with primary angioplasty. Am Heart J. 2004:148(4):655-62.

46. Grabowski M, Filipiak KJ, Malek LA, Karpinski G, Huczek Z, Stolarz P, Spiewak M, Kochman J, Rudowski R, Opolski G. Admission B-type natriuretic peptide assessment improves early risk stratification by Killip classes and TIMI risk score in patients with acute ST elevation myocardial infarction treated with primary angioplasty. Int J Cardiol. 2007;115(3):386-90.

47. Eggers KM, Lagerqvist $B$, Venge $P$, Wallentin $L$, Lindahl $B$. Prognostic value of biomarkers during and after non-ST-segment elevation acute coronary syndrome. J Am Coll Cardiol. 2009;54(4):357-64.

48. Krumholz HM, Chen J, Chen YT, Wang Y, Radford MJ. Predicting one-year mortality among elderly survivors of hospitalization for an acute myocardial infarction: results from the Cooperative Cardiovascular Project. J Am Coll Cardiol. 2001;38(2):453-9.

49. Singh M, Reeder GS, Jacobsen SJ, Weston S, Killian J, Roger VL. Scores for post-myocardial infarction risk stratification in the community. Circulation. 2002;106(18):2309-14.

50. Hwang D, Lee JM, Yang S, Chang M, Zhang J, Choi KH, Kim CH, Nam CW, Shin ES, Kwak JJ, et al. Role of post-stent physiological assessment in a risk prediction model after coronary stent implantation. JACC CardiovasC Interv. 2020;13(14):1639-50.
51. Zheng YY, Wu TT, Gao Y, Guo QQ, Ma YY, Zhang JC, Xun YL, Wang DY, Pan Y, Cheng MD, et al. A novel ABC score predicts mortality in non-ST-segment elevation acute coronary syndrome patients who underwent percutaneous coronary intervention. Thrombosis Haemost. 2020;121:297-308.

52. Antman EM, Cohen M, Bernink PJLM, McCabe CH, Horacek T, Papuchis G, Mautner B, Corbalan R, Radley D, Braunwald E. The TIMI Risk Score for unstable Angina/Non-ST elevation MIA method for prognostication and therapeutic decision making. JAMA. 2000;284(7):835-42.

53. Lev El, Kornowski R, Vaknin-Assa H, Porter A, Teplitsky I, Ben-Dor I, Brosh D, Fuchs S, Battler A, Assali A. Comparison of the predictive value of four different risk scores for outcomes of patients with ST-elevation acute myocardial infarction undergoing primary percutaneous coronary intervention. Am J Cardiol. 2008;102(1):6-11.

54. Kao Y-T, Hsieh Y-C, Hsu C-Y, Huang C-Y, Hsieh M-H, Lin Y-K, Yeh J-S. Comparison of the TIMI, GRACE, PAMI and CADILLAC risk scores for prediction of long-term cardiovascular outcomes in Taiwanese diabetic patients with ST-segment elevation myocardial infarction: From the registry of the Taiwan Society of Cardiology. PLoS ONE. 2020;15(2):e0229186-e0229186.

55. Chen C, Hsieh Y, Hsieh M, Lin Y, Huang C, Yeh J. Predictive power of inhospital and long-term mortality of the GRACE, TIMI, revised CADILLAC and PAMI Score in NSTEMI patients with diabetes - data from TSOC ACSDM registry. Acta Cardiol Sin. 2020;36(6):595-602.

\section{Publisher's Note}

Springer Nature remains neutral with regard to jurisdictional claims in published maps and institutional affiliations.
Ready to submit your research? Choose BMC and benefit from:

- fast, convenient online submission

- thorough peer review by experienced researchers in your field

- rapid publication on acceptance

- support for research data, including large and complex data types

- gold Open Access which fosters wider collaboration and increased citations

- maximum visibility for your research: over 100M website views per year

At BMC, research is always in progress.

Learn more biomedcentral.com/submissions 